\title{
The burial efficiency of organic carbon in the sediments of Lake Kinneret
}

\section{Journal Article}

\section{Author(s):}

Sobek, Sebastian; Zurbrügg, Roland; Ostrovsky, Ilia

Publication date:

2011-08

Permanent link:

https://doi.org/10.3929/ethz-b-000038670

Rights / license:

In Copyright - Non-Commercial Use Permitted

Originally published in:

Aquatic Sciences 73(3), https://doi.org/10.1007/s00027-011-0183-x 


\title{
The burial efficiency of organic carbon in the sediments of Lake Kinneret
}

\author{
Sebastian Sobek $\cdot$ Roland Zurbrügg • \\ Ilia Ostrovsky
}

Received: 2 July 2010/ Accepted: 14 January 2011 / Published online: 13 February 2011

(C) Springer Basel AG 2011

\begin{abstract}
Even though lake sediments constitute a significant long-term carbon sink, studies on the regulation of carbon burial in lakes sediments have, to date, been surprisingly few. We investigated to what degree the organic carbon (OC) being deposited onto the bottom of Lake Kinneret (Israel) is buried in the sediment at four different sites with varying degrees of oxygenation and varying supply of allochthonous particles from the River Jordan. For estimation of the OC burial efficiency (OC BE), i.e., the ratio between buried and deposited OC, we calculated OC burial from dated sediment cores, and calculated OC deposition using three different approaches. Calculation of OC deposition from sediment trap-derived mass deposition rates multiplied with the $\mathrm{OC}$ content of surface sediment yielded OC BE values that were at odds with published values for sediments dominated by autochthonous OC
\end{abstract}

S. Sobek $(\bowtie) \cdot R$. Zurbrügg

Eawag, Swiss Federal Institute of Aquatic Science

and Technology, Kastanienbaum, Switzerland

e-mail: sebastian.sobek@ebc.uu.se

S. Sobek $\cdot$ R. Zurbrügg

Institute of Biogeochemistry and Pollutant Dynamics,

ETH, Swiss Federal Institute of Technology Zurich,

Zürich, Switzerland

Present Address:

S. Sobek

Department of Ecology and Genetics, Limnology,

Uppsala University, Uppsala, Sweden

I. Ostrovsky

Israel Oceanographic and Limnological Research,

Yigal Allon Kinneret Limnological Laboratory, Midgal, Israel sources. Calculation via sediment trap data on organic matter flux collected within the Lake Kinneret monitoring program, as well as calculation of OC deposition as the sum of OC burial plus OC mineralization, returned fairly congruent estimates of OC BE (range 10-41\%), but only if the sediment trap data were corrected for the proportion of resuspended particles in the traps. Differences in OC BE between sites were small, indicating that OC source (common to all sites) was a more important regulator of OC BE in Lake Kinneret than oxygen exposure or mineral particles characteristics.

Keywords Lake sediment - Carbon sequestration . Organic matter mineralization - Oxygen exposure . Mineral particle characteristics - Sediment resuspension

\section{Introduction}

Organic carbon (OC) being deposited onto the sediment surface will either be mineralized to $\mathrm{CO}_{2}$ or $\mathrm{CH}_{4}$ by heterotrophic microbes, or it will be buried in the sediments. OC burial in marine sediments constitutes a significant carbon sink of about $0.1 \mathrm{Pg} \mathrm{C}$ year $^{-1}$ (IPCC 2007), and has over geological time lead to the accumulation of vast stocks of fossil carbon. Accordingly, many studies have tried to understand the factors regulating OC burial in marine sediments (Burdige 2007). The burial of OC in lake sediments, on the other hand, has received much less attention, even though the annual OC burial in lake sediments was estimated to amount to about $50 \%$ of the annual OC burial in the entire ocean (Dean and Gorham 1998). Considering that lakes cover only about $2 \%$ of the earth surface, as compared to $71 \%$ by the ocean, it becomes 
evident that lake sediments represent a very efficient OC sink. In spite of this apparently strong and efficient OC sink in lake sediments, studies on OC burial in lakes were rather fragmented, and the reported burial rates range over two orders of magnitude (Downing et al. 2008; Kortelainen et al. 2004; Mulholland and Elwood 1982). For that reason, and possibly also for their small areal extent, lakes have been disregarded in models of the global carbon cycle. Recently, the importance of the lake sediment OC sink has received increased recognition (Battin et al. 2009; Cole et al. 2007; Tranvik et al. 2009).

An important parameter describing the strength of the lake sediment carbon sink is the organic carbon burial efficiency (OC BE), i.e., the proportion of the deposited OC that escapes mineralization by its permanent burial. The OC BE is calculated from OC burial (i.e., the mass accumulation rate of $\mathrm{OC}$ in the sediment) and OC deposition rates (Hartnett et al. 1998). The latter is either derived from sediment traps, or can be calculated as the sum of $\mathrm{OC}$ burial and $\mathrm{OC}$ mineralization (i.e., evasion of $\mathrm{CO}_{2}$ and $\mathrm{CH}_{4}$ from the sediment). The $\mathrm{OC} \mathrm{BE}$, therefore, depends on all factors affecting $\mathrm{OC}$ deposition and $\mathrm{OC}$ mineralization. Only recently have we started to gain a better understanding of the regulation of $\mathrm{OC} \mathrm{BE}$ in lake sediments. On the one hand, OC mineralization in lake sediments was shown to be strongly positively related to temperature (Gudasz et al. 2010), implying that the OC BE decreases with increasing temperature. On the other hand, oxygen exposure time and organic matter source (autochthonous vs. allochthonous) were identified as important regulators of OC BE in lake sediments (Sobek et al. 2009), such that a short oxygen exposure time and a high share of allochthonous organic matter promote OC burial, while a long oxygen exposure time and a high share of autochthonous organic matter promote OC mineralization. Further, the sorption of organic matter onto the surfaces of mineral particles, an important mechanism of OC preservation in marine sediments (Keil et al. 1994; Rothman and Forney 2007), was found to be a less important regulator of $\mathrm{OC} \mathrm{BE}$ in lake sediments (Sobek et al. 2009).

Lake Kinneret (Israel) was chosen as part of that previous study (Sobek et al. 2009) because it is a subtropical lake with a high level of plankton primary production, extended periods of hypolimnetic anoxia, and inflow of catchment-derived suspended particles from the Jordan River (Serruya 1978). All of these characteristics (temperature, organic matter source, oxygen exposure and mineral particle characteristics) were hypothesized to affect the OC BE. It turned out that some Lake Kinneret sediments behaved differently compared to other lake sediments: at the deepest station, OC BE was much higher than for other lake sediments with comparable organic matter source (plankton debris) and similarly short oxygen exposure times. At the Jordan River inflow, OC BE was much lower than that at similar sites in other lakes receiving high riverine load (Sobek et al. 2009). Evidently, even though we have started to gain some insights into the regulation of OC BE in lake sediments (Gudasz et al. 2010; Sobek et al. 2009), there still are significant gaps in our present knowledge.

The main purpose of this paper is to give a detailed account of OC BE in Lake Kinneret to better understand why some sites in Lake Kinneret behaved differently from comparable sites in terms of OC BE. After critically revisiting the previous analysis, we were able to reconcile $\mathrm{OC}$ BE in Lake Kinneret with findings in other lakes. We further highlight the importance of independent determinations of OC deposition in turbulent systems, as well as the importance to differentiate between mineral and organic matter sources to the sediment.

\section{Methods}

\section{Site description}

Lake Kinneret is located in the central part of the AfroSyrian Rift Valley in northern Israel (Fig. 1), with a maximum water level of $-209 \mathrm{~m}$ above sea level, a maximum depth of $44 \mathrm{~m}$, a surface area of $168 \mathrm{~km}^{2}$, and a water retention time of $\sim 10$ years (Serruya 1978). The lake is monomictic, with stratification typically from April to December and holomixis from January to March. The epilimnion shows an annual temperature range of $14-30^{\circ} \mathrm{C}$, while the hypolimnion temperature stays constantly at $14-16^{\circ} \mathrm{C}$ throughout the year. Lake Kinneret is an eutrophic lake with an annual phytoplankton primary production of about $600 \mathrm{~g} \mathrm{C} \mathrm{m}^{-2}$ year $^{-1}$ (Berman et al. 1995). High temperature and productivity result in high rates of oxygen consumption, and hypolimnetic anoxia develops quickly after onset of stratification (Eckert and Conrad 2007). After onset of thermal stratification, the internal nutrient load from the anoxic hypolimnion and the $\sim 12$ to $16 \mathrm{~m}$ thick epilimnion is very limited. Still, boundary mixing associated with strong wind-induced internal wave movements (seiches) occurring in the lake between May and September enable the exchange of water and solutes between the upper and lower water masses near the lake boundaries (Ostrovsky and Yacobi 2010; Ostrovsky et al. 1996). Sedimentation patterns have been dominated by blooms of the phytoplankton Peridinium gatunense, even though these blooms have been absent during the last years. The Jordan River is the main source of water to the lake, and delivers about $80 \%$ of the suspended particle load from the catchment. Inflow of suspended allochthonous matter from 
the Jordan River is highest during winter and spring, and deposition of allochthonous particles is highest in the area close to the Jordan River inflow (Koren and Klein 2000). Seiching also affects sedimentation patterns by causing hypolimnetic bottom currents that resuspend organic particles and nutrients from the sediment surface. Due to frequent resuspension, sediment experiences significant lateral deposition-resuspension cycles, resulting in substantial focusing of sediment towards the center of the lake basin (Ostrovsky and Yacobi 1999).

\section{Sampling}

We conducted two sediment sampling campaigns, one after the establishment of thermal stratification (30 April-3 May 2007) and one during holomixis (21-28 February 2008). Sediments were sampled from four sites using a gravity corer. Typically, four replicate cores were sampled from each site. Three of the sites were above the thermocline and situated at increasing distance from the Jordan River inlet; the fourth site was in the middle of the lake (Fig. 1). The characteristics of these sites are presented in Table 1. Hence, these four sites represent areas of different sedimentological regime with respect to influence from the Jordan River and oxygen exposure. After retrieval, cores

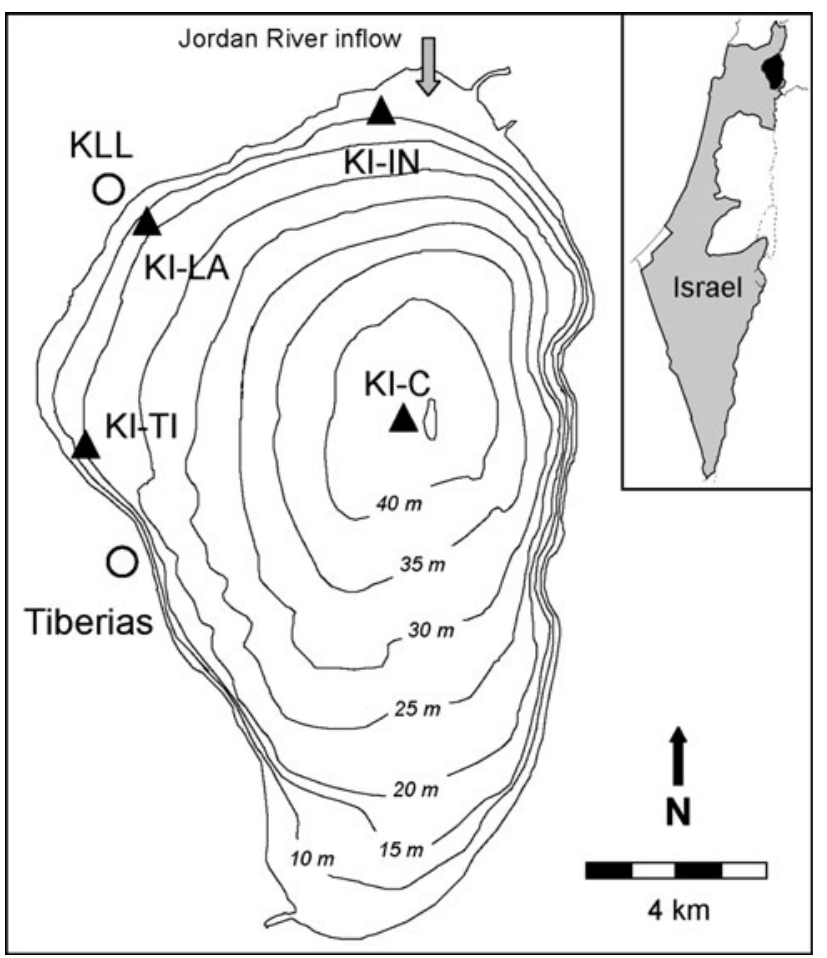

Fig. 1 Bathymetric map of Lake Kinneret with sampling sites (triangles). KI-IN is at the inlet of the Jordan River, KI-LA is close to the Kinneret Limnological Laboratory (KLL), KI-TI is close to the town of Tiberias, and KI-C is at the center of the lake. See Table 1 for sampling site coordinates and characteristics were sealed with plastic caps, stored on ice, and transported to the lab for immediate analysis of oxygen microprofiles.

Oxygen microprofiling

Profiles of oxygen concentration in the sediment porewater were measured using oxygen micro-optodes (tip size $<50 \mu \mathrm{m}$; PreSens) mounted on a computer-controlled micromanipulator (Newport) that moved the micro-optodes vertically in step sizes of 0.1 or $0.2 \mathrm{~mm}$. Measurement commenced usually $1-2 \mathrm{~h}$ after retrieving the core, and during this time, the cores were kept cool and dark, hence bottom water oxygen concentrations in the core were probably similar to in situ conditions. For measurement, most of the water overlying the sediment was carefully siphoned off, leaving about $5 \mathrm{~cm}$ of water column above the sediment. In each core, 2-3 oxygen profiles were recorded. At least two cores from each site were used for measurement of oxygen profiles. Measurements were conducted as close to in situ temperature as possible, and occasionally observed moderate temperature increases during measurement were not expected to affect the measured profiles to any large extent during the short time of measurement. The oxygen sensors were calibrated using water-saturated air and an oxygen-free solution (1:1 mixture of $0.1 \mathrm{~mol} \mathrm{~L}^{-1}$ sodium ascorbate and $0.1 \mathrm{~mol} \mathrm{~L}^{-1}$ $\mathrm{NaOH})$. Analytical precision was $\pm 0.5 \%$. In addition, bottom water oxygen concentration was determined by Winkler titration. The oxygen penetration depth was calculated as the difference in distance between the sedimentwater interface (defined from the shape and the standard deviations of the oxygen profile; Archer et al. 1989) and the depth of onset of anoxia (dissolved oxygen concentration below detection limit).

Sediment analysis

Sediment was sliced into $1 \mathrm{~cm}$ thick slices, at $1 \mathrm{~cm}$ intervals for the top $10 \mathrm{~cm}$, every second $\mathrm{cm}$ between 10 and $20 \mathrm{~cm}$ depth, and so on. Water content of the sediment was measured by weighing samples both wet and after freeze drying. Contents of total carbon and nitrogen were measured by high-temperature catalytic oxidation using a LECO CHNS-932. Inorganic carbon concentrations were measured on a coulometer after acidification with $2 \mathrm{M}$ perchloric acid (UIC). The organic carbon (OC) content was then calculated as the difference between total and inorganic carbon. Analytical precision was $\pm 1 \%$.

Dry bulk density $(\rho)$ of the sediment was calculated from the OC content (Müller et al. 2005), assuming that the sediment is a two-phase mixture between silicate and carbonate minerals (density about $2.65 \mathrm{~g} \mathrm{~cm}^{-3}$ ) and organic matter (density about $1 \mathrm{~g} \mathrm{~cm}^{-3}$ ): 
Table 1 Sampling sites, average sediment characteristics, and sedimentation rates in Lake Kinneret

\begin{tabular}{|c|c|c|c|c|c|c|c|c|c|c|}
\hline Site & ${ }^{\circ} \mathrm{N}$ & ${ }^{\circ} \mathrm{E}$ & $\begin{array}{l}\text { Depth } \\
(\mathrm{m})\end{array}$ & OC (\%) & $\mathrm{C} / \mathrm{N}$ & $\begin{array}{l}\text { Dry density } \\
\left(\mathrm{g} \mathrm{cm}^{-3}\right)\end{array}$ & Porosity & $\begin{array}{l}\text { Mineral surface } \\
\text { area }\left(\mathrm{m}^{2} \mathrm{~g}^{-1}\right)\end{array}$ & $\begin{array}{l}\text { Median grain } \\
\text { size }(\mu \mathrm{m})\end{array}$ & $\begin{array}{l}\text { Sedimentation rate } \\
\left(\mathrm{mm} \mathrm{year}^{-1}\right)\end{array}$ \\
\hline KI-IN & 32.86521 & 35.53910 & 7.3 & 1.6 & 10.9 & 2.56 & 0.70 & 36.6 & 0.86 & $6.3^{\mathrm{a}}$ \\
\hline KI-LA & 32.86653 & 35.55168 & 12.5 & 1.9 & 10.8 & 2.55 & 0.74 & 18.9 & 0.88 & $2.0^{\mathrm{b}}$ \\
\hline KI-TI & 32.80383 & 35.53327 & 11 & 1.5 & 9.1 & 2.57 & 0.71 & 19.6 & 0.79 & $2.8^{\mathrm{c}}$ \\
\hline KI-C & 32.82176 & 35.58903 & 40 & 3.9 & 12.2 & 2.45 & 0.87 & 20.7 & 1.08 & $4.5^{\mathrm{d}}$ \\
\hline
\end{tabular}

Sedimentation rates were derived from the literature and from measured profiles of ${ }^{210} \mathrm{~Pb}$ and ${ }^{137} \mathrm{Cs}$

a Average from Stiller (1979) and Stiller and Imboden (1986)

b Average from Stiller and Imboden (1986) and own data

${ }^{c}$ Own data

d Average from Stiller (1979), Erel et al. (2001) and own data

$\rho\left(\mathrm{g} \mathrm{cm}^{-3}\right)=-0.0523 \cdot \mathrm{OC}(\%)+2.65$

We also measured the dry bulk density in 12 samples using a pycnometer. The difference between calculated and measured density was on average $3 \%$, and did not affect the estimates of OC burial.

From bulk dry density $\left(\rho, \mathrm{g} \mathrm{cm}^{-3}\right)$ and water content $(w c, \%)$, we then calculated porosity $(\Phi)$ as follows:

$\Phi=\frac{w c}{(w c+(1-w c) \cdot \rho)}$

Sedimentation rates were determined from depth profiles of ${ }^{210} \mathrm{~Pb}$ and ${ }^{137} \mathrm{Cs}$, analyzed by gamma spectrometry using germanium detectors (Canberra). At site KI-IN, the depth profiles of ${ }^{210} \mathrm{~Pb}$ and ${ }^{137} \mathrm{Cs}$ could not be used for dating, probably due to the very heterogeneous sedimentation regime in the vicinity of the Jordan River inlet zone. For the other sites, we calculated the average sedimentation rate from our own data and published data, if available (Erel et al. 2001; Stiller 1979; Stiller and Imboden 1986), to better represent average sedimentation regime at the coring sites (Table 1).

The mineral surface area (MSA) was determined for two layers at each site $(0-1$ and $4-5 \mathrm{~cm})$ by means of $\mathrm{N}_{2}$ adsorption at $-196^{\circ} \mathrm{C}$ on a Sorptomatic 1990 (Thermo Electron Corporation), according to the BET method (Brunauer et al. 1938). Organic matter was removed by thermal oxidation at $350^{\circ} \mathrm{C}$ for $12 \mathrm{~h}$ (Mayer 1999). To remove water vapor prior to adsorption analysis, each sample was evacuated at $100^{\circ} \mathrm{C}$ until pressure was $<0.02 \mathrm{~Pa}$, and then evacuated at $100^{\circ} \mathrm{C}$ for another $2 \mathrm{~h}$. For calculation of BET parameters, six points within the linear part of the adsorption isotherm were used.

We also analyzed the size and elemental composition of mineral particles in surface sediment at the four sites using environmental scanning electron microscopy (ESEM) (Sobek and Kägi, unpublished data). Briefly, a sediment sample is pulled onto a filter after removal of organic matter, and the filter is then introduced into an ESEM equipped with backscattered X-ray detector. Automated image analysis detects, measures the size of, and records the X-ray spectrum of about 1,000 individual mineral particles. From these data, mineral grain size distribution and abundance of different mineral classes can be derived.

\section{Calculations}

The burial efficiency of organic carbon (OC BE, \%) was calculated as the ratio between $\mathrm{OC}$ burial (i.e., mean mass accumulation rate in the sediment, $\mathrm{g} \mathrm{C} \mathrm{m}^{-2}$ year $^{-1}$ ) and $\mathrm{OC}$ gross sedimentation (i.e., mean mass deposition rate onto the sediment surface, $\mathrm{g} \mathrm{C} \mathrm{m}^{-2}$ year $^{-1}$ ). OC burial was calculated from OC content, density and porosity of sediment layers $>25$-year-old, and the sedimentation rate. Gross sedimentation was derived from sediment traps using the mass deposition data from Koren and Klein (2000), which cover all sites of the present study, and measured OC content in surface sediment. In addition, we also used sediment trap-derived data on mass deposition and loss on ignition derived from a long-term monitoring program (1998-2008) at sites KI-LA and KI-C (Ostrovsky, unpublished data). OC content in deposited material was calculated by multiplying loss on ignition with 0.5 . We also calculated gross sedimentation from the sum of OC burial and OC mineralization, which gives a estimate of OC deposition independent of potential sediment trap artifacts (e.g., overtrapping due to resuspension). OC mineralization $\left(\mathrm{g} \mathrm{C} \mathrm{m}^{-2}\right.$ year $^{-1}$ ) at the shallow sites (KI-IN, KI-LA and KI-TI) was calculated from measured porewater profiles of oxygen using Fick's first law of diffusion and a respiratory quotient of 0.9 (Granéli 1979), assuming that oxic respiration is the main pathway of OC degradation in the permanently oxygenated shallow sites. Methane diffusive flux from the sediment to the water constituted at most $3 \%$ of oxic OC mineralization at the shallow sites (derived from methane porewater profiles in two cores at each site, 
data not shown; for method details, see Sobek et al. 2009), confirming this assumption. At the deep site (KI-C), we calculated oxic OC mineralization for the 3 months of holomixis from measured oxygen profiles, and anoxic OC mineralization for the 9 months of stratification from published rates of sulfate reduction and methanogenesis (Eckert and Conrad 2007; Hadas and Pinkas 1995). Oxygen exposure time was calculated by dividing the mean oxygen penetration depth by the sedimentation rate. All errors represent the $95 \%$ confidence interval, calculated using ordinary error propagation.

\section{Results}

The cores taken at the three shallow-water sites were relatively similar in their OC content (mean 1.6-1.9\%), while the core from the deep site (KI-C) had a higher OC content (3.9\%; Table 1). Also in terms of density, porosity and grain size, the shallow sites were similar to each other (Table 1). Downcore profiles of OC indicate higher levels in the top sediment layers, with a decline towards deeper sediment layers, except at the site closest to the Jordan River inlet (Fig. 2). The molar $\mathrm{C} / \mathrm{N}$ ratio follows the downcore decline in OC at the deepest site (KI-C), while the $\mathrm{C} / \mathrm{N}$ ratio exhibits no clear trends over depth at the shallow sites.

Oxygen penetration depth was generally low in Lake Kinneret, ranging between 1.2 and $3.1 \mathrm{~mm}$ (Table 2, Fig. 3). Oxygen penetration depths were generally greater during mixing, and lower during stratification. In conjunction with sedimentation rates of several $\mathrm{mm}$ year ${ }^{-1}$ (Table 1), the overall shallow oxygen penetration depths translated into short oxygen exposure times (range, 2-10 months).

Mineral phase analyses show that there are clear differences between sediment deposited close to the Jordan River as compared to other sites. Close to the Jordan inflow at KI-IN, mineral surface area was roughly twice as high $\left(36.6 \mathrm{~m}^{2} \mathrm{~g}^{-1}\right)$ as compared to the other sites (range, 18.9-20.7 $\mathrm{m}^{2} \mathrm{~g}^{-1}$ ), even though mineral grain size was similar at KI-IN (Table 1). Also the mineralogical composition of the sediment grains, as determined by ESEM, indicated a strong difference between the shallow sites, in particular KI-IN, and the central basin (KI-C). The sediment at KI-IN contained a high share of heavy iron-rich silicates and rutile (titanium dioxide), both of which are of terrestrial origin. At site $\mathrm{KI}-\mathrm{C}$, in contrast, the sediment was richer in light silicates (containing sodium and potassium) and calcite, which are typical of plankton debris. Sites KI-LA and KI-TI were intermediate in their contents of these groups of minerals (data not shown).

Sedimentation rates were highest at KI-IN close to the River Jordan inlet $\left(6.3 \mathrm{~mm}_{\text {year }}{ }^{-1}\right)$, lower at the shallow sites KI-LA and KI-TI (2.0 and $2.8 \mathrm{~mm} \mathrm{year}^{-1}$, respectively), and intermediate at KI-C (4.5 $\mathrm{mm}^{\text {year }}{ }^{-1}$; Table 1$)$. These differences in sedimentation rate, as well as in OC content, density and porosity, resulted in different rates of OC burial, ranging between 15 and $72 \mathrm{~g} \mathrm{C} \mathrm{m}^{-2}$ year $^{-1}$ (Table 3). The OC BE was calculated using either sediment trap data from different sources, or OC mineralization data.
Fig. 2 Profiles of organic carbon (circles) and the molar ratio of carbon to nitrogen in organic matter (triangles) in Lake Kinneret sediments. a KI-IN, b KI-LA, c KI-LA, and d $\mathrm{KI}-\mathrm{C}$
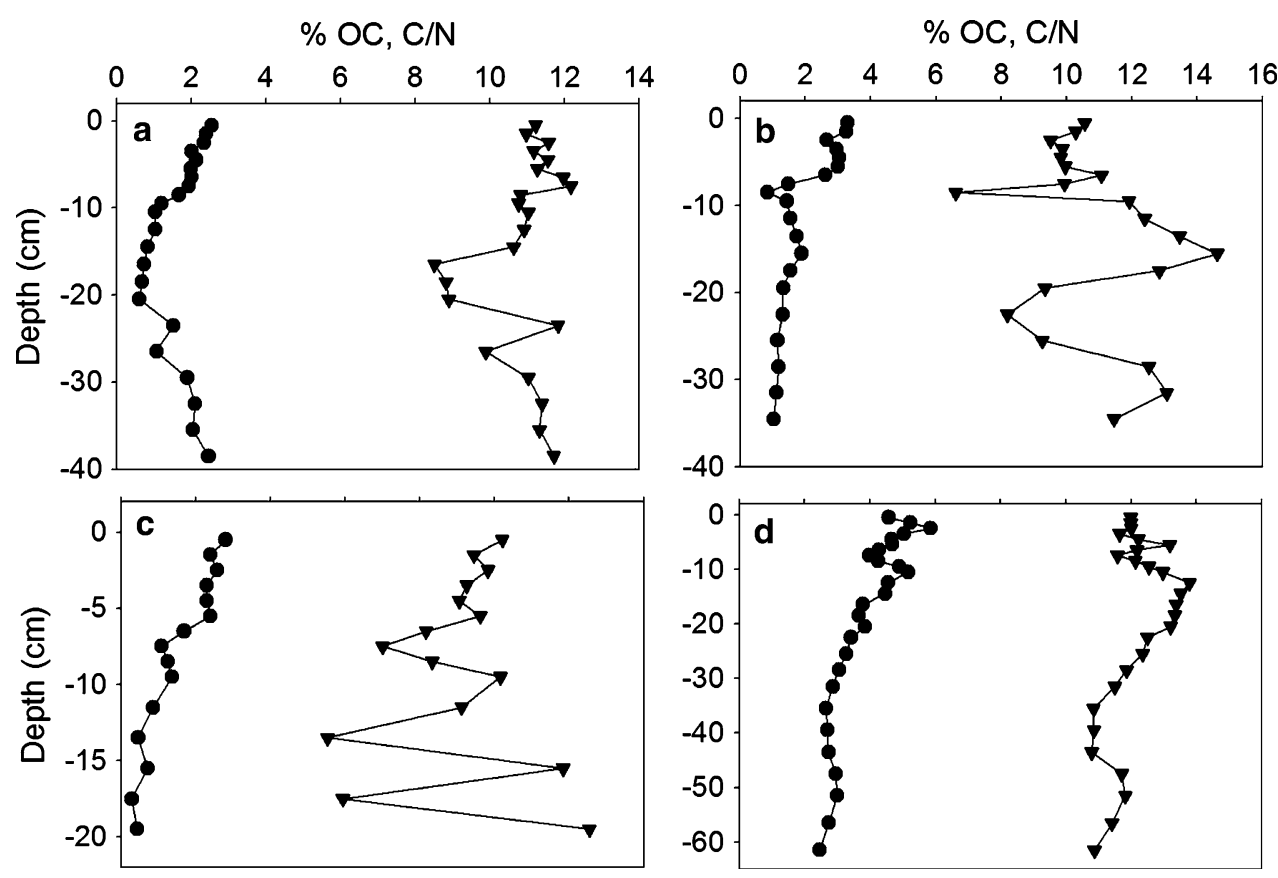
Table 2 Oxygen penetration depths (mean $\pm 95 \%$ confidence interval) and oxygen exposure time (OET) at different sites in Lake Kinneret

\begin{tabular}{lllll}
\hline Site & \multicolumn{2}{l}{ Oxygen penetration depth $(\mathrm{mm})$} & OET (years) \\
\cline { 2 - 4 } & $\begin{array}{l}\text { Stratification } \\
\text { period }\end{array}$ & $\begin{array}{l}\text { Mixing } \\
\text { period }\end{array}$ & $\begin{array}{l}\text { Annual } \\
\text { mean }\end{array}$ & \\
\hline KI-IN & $1.16 \pm 0.42$ & $2.34 \pm 0.24$ & $1.88 \pm 0.30$ & $0.30 \pm 0.05$ \\
KI-LA & $1.37 \pm 0.56$ & $2.06 \pm 0.26$ & $1.72 \pm 0.31$ & $0.84 \pm 0.15$ \\
KI-TI & $1.31 \pm 0.33$ & $1.95 \pm 0.13$ & $1.63 \pm 0.18$ & $0.58 \pm 0.06$ \\
KI-C & $1.73 \pm 0.21^{\text {a }}$ & $3.10 \pm 0.23$ & $0.78 \pm 0.06$ & $0.17 \pm 0.01^{\mathrm{b}}$ \\
\hline
\end{tabular}

See Table 1 and Fig. 1 for location of sampling sites

${ }^{a}$ Measured after $6 \mathrm{~h}$ aeration of overlying water

${ }^{b}$ Calculated assuming 3 months of mixing and 9 months of anoxia during stratification

The different estimates of $\mathrm{OC} \mathrm{BE}$ were widely variable (range, 4-63\%), both between sites and between the different ways of OC BE calculation (Table 3). These differences are discussed in detail below.

\section{Discussion}

In such a turbulent system as Lake Kinneret, the rate of delivery of new OC to the lake bottom is difficult to determine. Due to regularly recurring internal waves and seiches, resuspension is frequently responsible for a large share of particles caught in sediment traps of Lake Kinneret
(Ostrovsky and Yacobi 1999). Hence, using sediment trap data that have not been corrected for the extent of resuspended sediment caught in the traps returns overly high OC deposition rates (Ostrovsky and Yacobi 2010), which then yields $\mathrm{OC} \mathrm{BE}$ values that are exceedingly low at resuspension-prone sites (e.g., 4\% at KI-LA, Table 3). We therefore corrected the multiannual sediment trap data (available for sites KI-LA and KI-C) using the proportion of resuspended material in bottom traps as reported by Ostrovsky and Yacobi (1999, their Fig. 5). This correction reduces OC deposition rates by 80 and $40 \%$ at sites KI-LA and $\mathrm{KI}-\mathrm{C}$, respectively, resulting in considerably higher OC burial efficiencies (20\% instead of $4 \%$, and $41 \%$ instead of $21 \%$ at KI-LA and KI-C, respectively; Table 3); these values are in better accordance to OC BEs reported from lake sediments receiving predominately autochthonous OC (Sobek et al. 2009).

In an attempt to circumvent the problems associated with sediment traps in this turbulent lake, we also calculated OC deposition rates from the sum of OC burial and OC mineralization. For the shallow sites, which always are overlain by oxygenated water, we calculated OC mineralization from oxygen microprofiles, assuming that oxic respiration is the most important degradation pathway in shallow locations (see "Methods"). For the deep site (KI-C), we calculated oxic respiration from measured oxygen microprofiles for the approximate 3 months of holomixis. For the 9 months of anoxic sediments during stratification at KI-C, we estimated anaerobic respiration from published rates of sulfate reduction and methanogenesis (Hadas and Pinkas
Fig. 3 Examples of oxygen concentration profiles in the sediment porewater of Lake Kinneret measured during holomixis. a KI-IN, b KI-LA, c KI-LA, and d KI-C. The dashed lines indicate the sediment-water interface

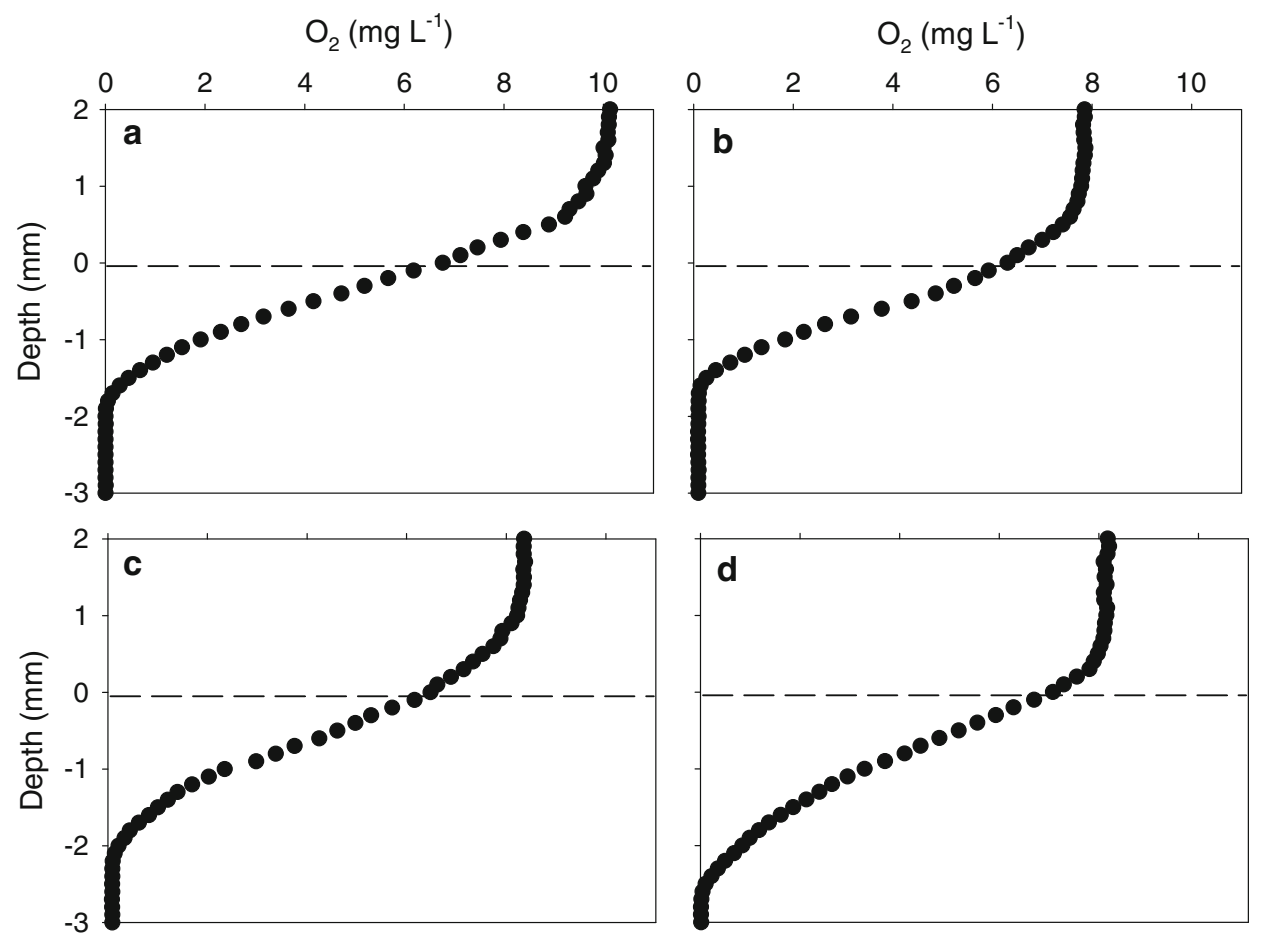


1995; Eckert and Conrad 2007), which are the most important anaerobic degradation pathways in Lake Kinneret. The resulting $\mathrm{OC} \mathrm{BE}$ estimates (i.e., $\mathrm{OC}$ burial divided by the sum of $\mathrm{OC}$ burial and $\mathrm{OC}$ mineralization) were similar to the $\mathrm{OC} \mathrm{BE}$ estimates calculated from the multiannual trap data, if the latter were corrected for resuspension (Table 3).

These calculations may be compared with the initial analysis of OC BE in Lake Kinneret (Sobek et al. 2009), which used published sediment trap-based dry mass deposition rates (Koren and Klein 2001), multiplied with the OC content in surficial sediment layers. At the shallow sites, the three different approaches of calculating OC BE agreed fairly well (Table 3, Fig. 3), returning burial efficiencies of about 10-30\%. At the deep site (KI-C), however, the OC BE of the initial analysis (63\%; Sobek et al. 2009) was considerably higher than both the burial efficiency calculated from multiannual trap data (if corrected for resuspension), and the burial efficiency calculated from OC mineralization (41 and 26\%, respectively). Hence, the two alternatively calculated estimates of OC BE presented here both indicate that in the initial analysis (Sobek et al. 2009), OC BE at site KI-C was overestimated. A recent evaluation of sediment trap deployments in Lake Kinneret supports that view, reporting an OC deposition (unaffected by resuspended matter) of about $173 \mathrm{~g} \mathrm{C} \mathrm{m}^{-2}$ year $^{-1}$ at KI-C (Ostrovsky and Yacobi 2010), which would return an OC BE at KI-C of about $31 \%$. As a consequence, an OC BE for KI-C in the range of 26-41\% follows the relationship between oxygen exposure time and OC BE reported by Sobek et al. (2009), as expected for a sediment that receives OC mainly from plankton debris (Fig. 4).

On the other hand, sediment close to the River Jordan inlet (KI-IN) had much lower OC BE ( 30\%) than comparable sites at river mouths in other lakes (e.g. Lake Constance, $\sim 80 \%$; Sobek et al. 2009), where particles deposited onto the sediment originate mainly from allochthonous sources. The comparatively low OC burial efficiency at KI-IN was corroborated if alternatively calculated from OC mineralization (29\%; Table 3). Our data suggest that mineral particles at KI-IN are derived from another source than at the other sites, as indicated by higher mineral surface area and higher sedimentation rate at KI-IN (Table 1). Further, electron microscope analyses of the mineral particles at the different sites support that at KI-IN, a larger share of the sediment is derived from allochthonous particles than at the other sites (see "Results"). On the other hand, while the mineral particles at KI-IN originate mainly from riverine input, the organic matter in KI-IN is probably largely derived from autochthonous sources, as phytoplankton production in the area of the River Jordan inlet is usually above seasonal means for Lake Kinneret

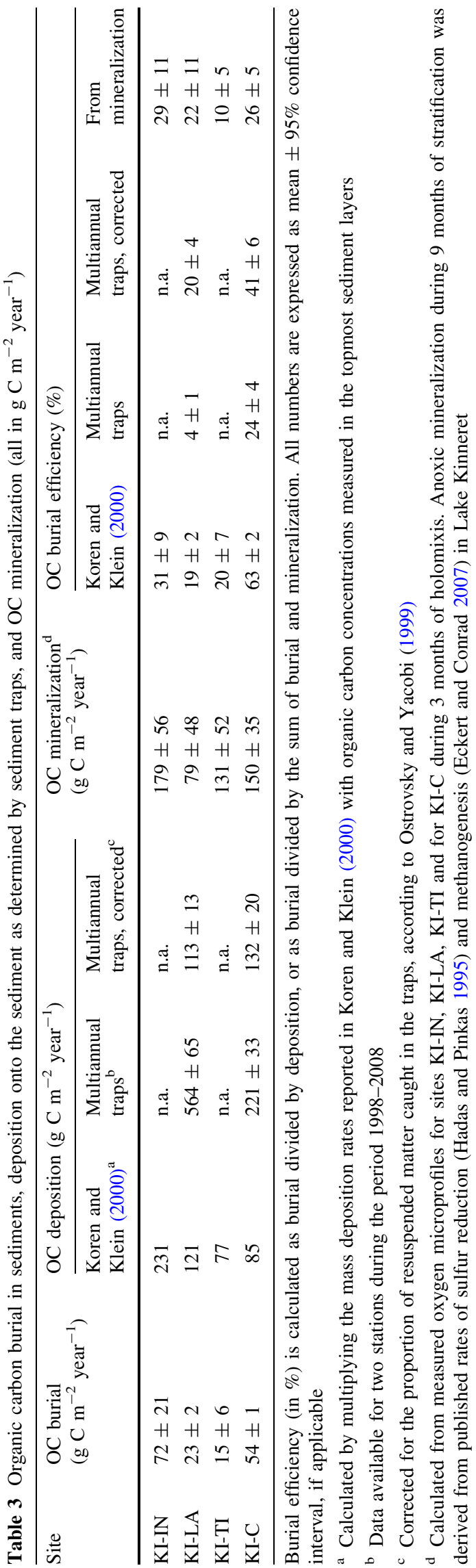




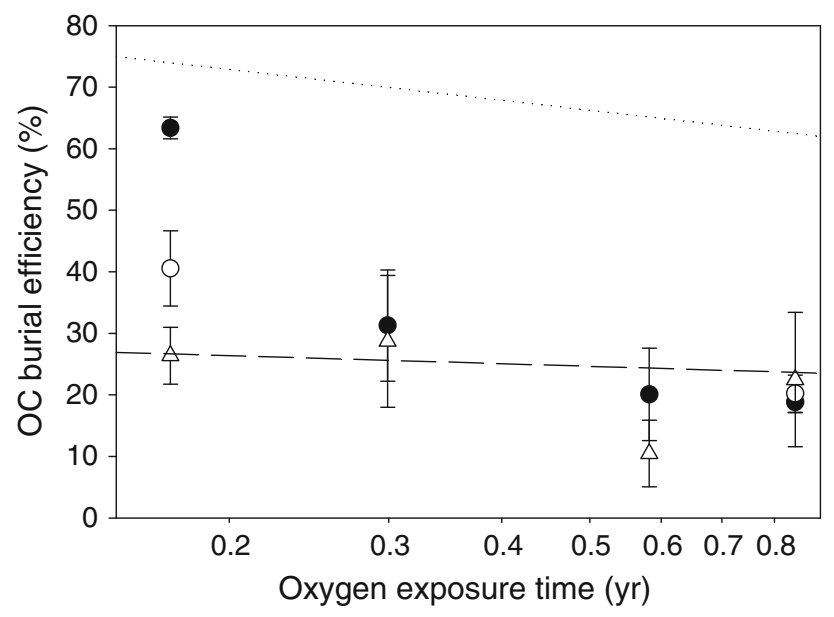

Fig. 4 Oxygen exposure time plotted against OC burial efficiency, calculated from either sediment trap data by Koren and Klein (2000) and surface sediment OC concentration (closed circles), or from multiannual sediment trap data corrected for resuspension (open circles), or from OC mineralization (open triangles). Error bars denote the $95 \%$ confidence interval. The lines show the relationships between oxygen exposure time and OC burial efficiency for sediments dominated by autochthonous organic matter (dashed line) or by allochthonous organic matter (dotted line) according to Sobek et al. (2009)

(Ostrovsky and Yacobi 2009). Given that the organic matter content of sinking plankton debris (mean, 35\% at $\mathrm{KI}-\mathrm{C}$ ) is much higher than that of suspended particles in the River Jordan (4\%; Yacobi and Ostrosky 2008; Koren and Klein 2000), it becomes evident that a substantial share of the organic matter deposited at KI-IN is of autochthonous origin. Hence, the sediment deposited at KI-IN largely is a mixture of allochthonous mineral particles supplied from the River Jordan, and autochthonous organic matter supplied from plankton debris. This could explain the comparatively low $\mathrm{OC} \mathrm{BE}$ at this site, as autochthonous organic matter is prone to mineralization rather than burial (Burdige 2007; Sobek et al. 2009). Accordingly, it seems that organic matter characteristics, rather than mineral particle characteristics, determine the OC BE at KI-IN.

Based on the above analysis, we conclude that $\mathrm{OC} \mathrm{BE}$ calculated from either multiannual trap data corrected for resuspension, or from $\mathrm{OC}$ mineralization, give the most reliable estimates. The $\mathrm{OC}$ BE estimates derived from published mass deposition rates (Koren and Klein 2000) and surface sediment $\mathrm{OC}$ content are probably less reliable (Table 3), as the OC content of surface sediment is lower than that of sinking particles (5 and $18 \%$, respectively), owing to high mineralization intensity in freshly deposited organic matter (Ostrovsky 2000). Likewise, using sediment trap data without correcting for resuspension does not result in reliable results in such a turbulent system as Lake Kinneret. When plotting the oxygen exposure time against the most reliable estimates of OC BE (Fig. 4), the studied sites follow the relationship previously described for other lake sediments receiving predominantly autochthonous input (Sobek et al. 2009). Even though a thorough statistical analysis is not meaningful due to the relatively short gradient in oxygen exposure time, it seems that also within Lake Kinneret, oxygen exposure time may affect the burial efficiency of organic carbon in the sediment; average OC $\mathrm{BE}$ seems to be somewhat higher at short oxygen exposure time at sites KI-C and KI-IN (Fig. 4). Similarly to other lake sediments dominated by autochthonous organic matter, however, the potential effect of oxygen exposure time on OC BE at KI-C and KI-IN is not very strong, compared to sediments dominated by allochthonous OC (Sobek et al. 2009). Alternatively, the relatively long pre-depositional history of the sediment at KI-C (Ostrovsky and Yacobi 1999) could promote burial, as frequent resuspension cycles have been reported to enhance OC mineralization (Hulthe et al. 1998), such that a large share of preferentially preserved ("left-over") organic matter may be deposited at KI-C. Further, we can not exclude positive effects on OC $\mathrm{BE}$ by organic matter sorption onto mineral surfaces at site KI-IN (Table 1, Fig. 4). Either way, our analysis shows that $\mathrm{OC}$ BE in Lake Kinneret is relatively similar between the different sites (Table 3), in spite of their differences in oxygen exposure time and mineral phase characteristics, indicating that the similar source of $\mathrm{OC}$ to all sites may the dominant regulating factor of OC BE in Lake Kinneret.

In coastal marine sediments, similar effects of organic matter source, resuspension, and oxygen exposure have been observed. Accordingly, phytoplankton-derived organic matter is preserved to a smaller degree than is terrestrialderived organic matter (Burdige 2007), and frequent resuspension cycles and physical reworking of surficial sediment layers lead to high rates of OC mineralization and low OC BE in coastal deltaic sediments (Aller 1998). On the other hand, very high OC BE in deltaic sediment in the Gulf of Bengal was attributed to low oxygen availability, implying that even frequent resuspension cycles can not significantly promote OC mineralization if oxygen exposure time is short (Galy et al. 2007). Hence, it seems that similar mechanisms affect the preservation and mineralization of organic matter in both marine and freshwater sediments, even though physical, sedimentological and geochemical settings may be different.

While our study presents evidence that OC BE in Lake Kinneret sediments is on the order of $10-40 \%$ (Table 3), Eckert and Conrad (2007) found that OC mineralization in the hypolimnion of Lake Kinneret was comparable to, or even larger, than the OC deposition on the bottom at KI-C. However, our data clearly show a substantial burial flux at KI-C (Table 3), so the OC deposited onto the sediment can not be completely mineralized, as the results by Eckert and 
Conrad (2007) would suggest. This apparent contradiction could be resolved by sufficiently high mineralization in the hypolimnetic water column, in accordance with reports observable degradation of sinking particles in Lake Kinneret (Yacobi and Ostrovsky 2008). Similarly, only about $20 \%$ of the phytoplankton production of Lake Kinneret was exported from the mixed surface layer to the hypolimnion (Ostrovsky and Yacobi 2010), indicating that the particles exported from the mixed surface layer are probably sufficiently reactive to sustain sizeable mineralization rates even in the frequently oxygen-deficient hypolimnetic water column.

This study shows that after revisiting OC deposition data by using resuspension-corrected long-term sediment trap data, or by using the sum of OC burial and sediment mineralization rates, the $\mathrm{OC} \mathrm{BE}$ in Lake Kinneret sediments turned out to be similar to other lakes with predominantly autochthonous organic matter sources to the sediment, both in magnitude (Table 3 ) and in its relationship to oxygen exposure time (Fig. 4). It further illustrates the need for different approaches for the accurate estimation of OC deposition in turbulent aquatic systems, where resuspension can play an important role in the sedimentological regime. Also, it is important to consider that the sources of mineral particles and the source of organic matter to bottom sediments may be different, as shown for site KI-IN. Lastly, the similarity of OC BE across sites may be related to the similar OC source to all sites, namely plankton debris, while the differences between sites in oxygen exposure time and mineral phase composition did not seem to be important regulators of $\mathrm{OC} \mathrm{BE}$ in Lake Kinneret. While these conclusions were reached from a study of Lake Kinneret, it is very likely that they apply to the sediments of other lakes with similar physical and geochemical settings.

Acknowledgments We want to thank Werner Eckert and Mina Bizic for support during fieldwork, and Ralf Kägi for ESEM analyses. Financial support from the Swiss National Science Foundation (200020-112274) is acknowledged. This work was partially supported by Lake Kinneret Monitoring Program funded by the Israeli Water Commissioner and by a research grant from the Israeli Science Foundation (ISF Grant 627/07). S. Sobek acknowledges additional support from FORMAS (the Swedish Research Council for Environment, Agricultural Sciences and Spatial Planning).

\section{References}

Aller RC (1998) Mobile deltaic and continental shelf muds as suboxic, fluidized bed reactors. Mar Chem 61(3-4):143-155

Archer D, Emerson S, Smith CR (1989) Direct measurement of the diffusive sublayer at the deep-sea floor using oxygen microelectrodes. Nature 340(6235):623-626

Battin TJ, Luyssaert S, Kaplan LA, Aufdenkampe AK, Richter A, Tranvik LJ (2009) The boundless carbon cycle. Nature Geosci 2(9):598-600
Berman T, Stone L, Yacobi YZ, Kaplan B, Schlichter M, Nishri A, Pollingher U (1995) Primary production and phytoplankton in Lake Kinneret: a long-term record (1972-1993). Limnol Oceanogr 40(6):1064-1076

Brunauer S, Emmett PH, Teller E (1938) Adsorption of gases in multimolecular layers. J Am Chem Soc 60:309-319

Burdige DJ (2007) Preservation of organic matter in marine sediments: controls, mechanisms, and an imbalance in sediment organic carbon budgets? Chem Rev 107(2):467-485

Cole JJ, Prairie YT, Caraco NF, McDowell WH, Tranvik LJ, Striegl RG, Duarte CM, Kortelainen P, Downing JA, Middelburg JJ, Melack J (2007) Plumbing the global carbon cycle: Integrating inland waters into the terrestrial carbon budget. Ecosystems 10(1):171-184

Dean WE, Gorham E (1998) Magnitude and significance of carbon burial in lakes, reservoirs, and peatlands. Geology 26(6): 535-538

Downing JA, Cole JJ, Middelburg JJ, Striegl RG, Duarte CM, Kortelainen P, Prairie YT, Laube KA (2008) Sediment organic carbon burial in agriculturally eutrophic impoundments over the last century. Global Biogeochem Cycles 22:GB1018. doi: 1010.1029/2006GB002854

Eckert W, Conrad R (2007) Sulfide and methane evolution in the hypolimnion of a subtropical lake: a three-year study. Biogeochemistry 82(1):67-76

Erel Y, Dubowski Y, Halicz L, Erez J, Kaufman A (2001) Lead concentrations and isotopic ratios in the sediments of the Sea of Galilee. Environ Sci Technol 35(2):292-299

Galy V, France-Lanord C, Beyssac O, Faure P, Kudrass H, Palhol F (2007) Efficient organic carbon burial in the Bengal fan sustained by the Himalayan erosional system. Nature 450(7168): 407-410

Granéli HW (1979) A comparison of carbon dioxide production and oxygen uptake in sediment cores from four south Swedish lakes. Holarctic Ecol 2:51-57

Gudasz C, Bastviken D, Steger K, Premke K, Sobek S, Tranvik LJ (2010) Temperature-controlled organic carbon mineralization in lake sediments. Nature 466(7305):478-481

Hadas O, Pinkas R (1995) Sulfate reduction processes in sediments at different sites in Lake Kinneret, Israel. Microb Ecol 30(1):5566

Hartnett HE, Keil RG, Hedges JI, Devol AH (1998) Influence of oxygen exposure time on organic carbon preservation in continental margin sediments. Nature 391(6667):572-574

Hulthe G, Hulth S, Hall POJ (1998) Effect of oxygen on degradation rate of refractory and labile organic matter in continental margin sediments. Geochim Cosmochim Ac 62(8):1319-1328

IPCC (2007) Climate change 2007: the physical science basis. contribution of working group I to the fourth assessment report of the intergovernmental panel on climate change. Cambridge University Press, Cambridge, p 996

Keil RG, Montlucon DB, Prahl FG, Hedges JI (1994) Sorptive preservation of labile organic-matter in marine-sediments. Nature 370(6490):549-552

Koren N, Klein M (2000) Rate of sedimentation in Lake Kinneret, Israel: spatial and temporal variations. Earth Surf Proc Land 25(8):895-904

Kortelainen P, Pajunen H, Rantakari M, Saarnisto M (2004) A large carbon pool and small sink in boreal Holocene lake sediments. Glob Change Biol 10:1648-1653

Mayer LM (1999) Extent of coverage of mineral surfaces by organic matter in marine sediments. Geochim Cosmochim Acta 63:207-215

Mulholland PJ, Elwood JW (1982) The role of lake and reservoir sediments as sinks in the perturbated global carbon cycle. Tellus 34:490-499 
Müller B, Märki M, Schmid M, Vologina EG, Wehrli B, Wuest A, Sturm M (2005) Internal carbon and nutrient cycling in Lake Baikal: sedimentation, upwelling, and early diagenesis. Global Planet Change 46(1-4):101-124

Ostrovsky I (2000) The upper most layer of bottom sediments: sampling and artifacts. Arch Hydrobiol Spec Issues Advanc Limnol 55:243-255

Ostrovsky I, Yacobi YZ (1999) Organic matter and pigments in surface sediments: possible mechanisms of their horizontal distributions in a stratified lake. Can J Fish Aquat Sci 56(6): $1001-1010$

Ostrovsky I, Yacobi YZ (2009) Temporal evolution and spatial heterogeneity of ecosystem parameters in a subtropical lake. In: Ciraolo G, Ferreri GB, Napoli E (eds) Proceedings of the 13th International Workshop on Physical Processes in Natural Waters Palermo, Italy, 1-4 Sep, 2009

Ostrovsky I, Yacobi YZ (2010) Sedimentation flux in a large subtropical lake: spatiotemporal variations and relations to primary productivity. Limnol Oceanogr 55(5):1918-1931

Ostrovsky I, Yacobi YZ, Walline P, Kalikhman I (1996) Seicheinduced mixing: its impact on lake productivity. Limnol Oceanogr 41(2):323-332

Rothman DH, Forney DC (2007) Physical model for the decay and preservation of marine organic carbon. Science 316(5829): $1325-1328$
Serruya C (1978) Lake Kinneret. Dr. W. Junk bv Publishers, The Hague

Sobek S, Durisch-Kaiser E, Zurbrügg R, Wongfun N, Wessels M, Pasche N, Wehrli B (2009) Organic carbon burial efficiency in lake sediments controlled by oxygen exposure time and sediment source. Limnol Oceanogr 54(6):2243-2254

Stiller M (1979) Sedimentation patterns in Lake Kinneret. In: Isotopes in lake studies. IAEA International Atomic Energy Agency, Vienna, pp 273-285

Stiller M, Imboden DM (1986) ${ }^{210} \mathrm{~Pb}$ in Lake Kinneret waters and sediments: residence times and fluxes. In: Sly PG (ed) Sediments and water interactions. Springer-Verlag, New York, pp 501-511

Tranvik LJ, Downing J, Cotner J, Loiselle S, Striegl RG, Ballatore TJ, Dillon P, Finlay K, Fortino K, Knoll LB, Kortelainen P, Kutser T, Larsen S, Laurion I, Leech DM, McCallister SL, McKnight DM, Melack JM, Overholt E, Porter JA, Prairie Y, Renwick WH, Roland F, Sherman BS, Schindler DW, Sobek S, Tremblay A, Vanni MJ, Verschoor AM, von Wachenfeldt E, Weyhenmeyer GA (2009) Lakes and impoundments as regulators of carbon cycling and climate. Limnol Oceanogr 54(6, part 2):2298-2314

Yacobi YZ, Ostrovsky I (2008) Downward flux of organic matter and pigments in Lake Kinneret (Israel): relationships between phytoplankton and the material collected in sediment traps. J Plankton Res 30(10):1189-1202 